\title{
The Stock Market Integration of the US, Canadian, and the Japanese Markets: Before and After the Lehman Shock in the US
}

\author{
Chikashi Tsuji (Corresponding author) \\ Graduate School of Systems and Information Engineering \\ University of Tsukuba \\ 1-1-1Tennodai, Tsukuba, Ibaraki 305-8573, Japan \\ Tel: 81-29-853-2111Ｅ-mail: mail_sec_low@minos.ocn.ne.jp
}

Received: March28, 2012 Accepted: April11, 2012 Published: June 21, 2012

doi:10.5296/ber.v2i1.1976 URL: http://dx.doi.org/10.5296/ber.v2i1.1976

\begin{abstract}
The time-series developments of comovementsin stock returns between the Japanese markets and the US or Canadian markets are empirically examined. We investigate these covariations by dividing full sample periods into several sub-periods that are before and after the US Lehman Shock. In this paper, it is demonstrated that the connections of stock returns of the Japanese markets and the US or Canadian equity markets recently gradually increased. In addition, it is also clarified that in the sub-period right after theLehman Shock, these connections between stock returns ofthe Japanese and the US or Canadian equity markets highly increased.
\end{abstract}

Keywords: American stock markets, Canadian stock markets, International stock market integration,Japanese stock markets, Stock return comovements 


\section{Introduction}

Researchers and practitioners in the field of business and economics are more and more paying attention to the time-varying comovements of stock returns in international equity markets. This stock market integration is one of the important research topics in business, economics and finance. There are several excellent papers as to the international stock return comovements and international stock market integration. These studies are, for example, the researches by Solnik (1974), Bekaert and Harvey (1995), Allen and Gale (2000), Forbes and Rigobon (2002), Hardouvelis et al. (2006), Pukthuanthong and Roll (2009), Allen et al. (2012), and Billio et al. (2012).

Contrary to the existence of interesting preceding studies as above, as far as we know, there seem to be few academic research papers that carefully scrutinize the stock return relationships by focusing on the linkage between the Japanese stock markets and the US or Canadian markets. In addition, we consider that, there seem to be little study which examines the above connections by carefully dividing the analyzing periods into the time-periods that are before and after the US Lehman Shock.

With the above backgrounds and motivations, in this paper, it is attempted to analyze and discuss the time-series developments of stock return covariations between the Japanese equity markets and the US or Canadian markets. This is the primary concern in our study. In order to carefully examine these relationships, the stock indices data of the Morgan Stanley Capital International for the US and Canadian stock markets are used. In addition to the above, the data of the typical Japanese equity market index, the Tokyo Stock Price Index, are also used.

Our empirical tests in this paper offer the following interesting contributions. First of all, we statistically found that in the recent periods, the time-series comovements of stock returns between the Japanese equity markets and the US or Canadian markets gradually increased. Next, this paper further found that especially in the sub-period right after the US Lehman Shock, the time-varying connections between returns in these international equity markets generally increased. We note that our analysis is new because comparisons between the periods before and after the Lehman Shock are performed. Further, the analysis of the time-varying linkage between Canadian and the Japanese markets implemented in this paper is also quite unique.

Explaining the organization of this paper, the rest of the paper is firstly, Section 2 reviews the related literature briefly, secondly, Section 3explains the data we use, and thirdly, Section 4documents our research design. After that, Section 5explains our empirical results, Section 6documents and discusses the interpretation and implications from our analyses, and finally, Section 7 concludes the paper.

\section{Literature Review}

We consider that regarding the stock market integration, there would not be the perfect theory that explains all real world situations. This section briefly reviews several interesting literature, thus all studies below are empirical researches. First, Solnik (1974) investigated the 
price of risk in capital asset pricing models in an international context. The time period covered in the study was from March 1966 to April 1971. Next, Bekaert and Harvey (1995) found that a number of emerging equity markets exhibited the time-varying integration. We note that their focus was on the emerging stock markets. Further, Forbes and Rigobon (2002) investigated international stock markets by using international data. They insisted that after some adjustments, there was virtually no increase in their unconditional correlation coefficients during the 1997 Asian crisis, 1994 Mexican devaluation, and 1987 U.S. market crash. We also note here that their focus was not on the Lehman Shock. Hardouvelis et al. (2006) studied the influences of the launch of the single currency in Europe in January 1999 on the stock market integrations in Europe. Moreover, a recent study by Pukthuanthong and Roll (2009) derived a new integration measure based on the explanatory power of a multi-factor model and use it empirically to investigate recent trends in global stock market integration. However, their focus was not on the influence of the Lehman Shock. Finally, Billio et al. (2012) proposed several econometric measures of connectedness based on principal-components analysis and Granger-causality networks. We also note that their focus was on the finance and insurance sectors in the US. As above literature review indicates, our analysis is quite unique because in our study, comparisons between the periods before and after the Lehman Shock are focused. Further, our analysis of the time-varying linkages between Canadian and the Japanese markets in this paper is also quite unique since these linkages were little analyzed in preceding studies.

\section{Data}

Describing the data, we use the weekly stock returns calculated from the Morgan Stanley Capital International Indices. We also use the weekly stock returns derived from the Tokyo Stock Price Index. The above indices are all local currency basis, and all above data are obtained through the Nikkei Inc. Using the above data, we statistically inspect the equity return correlation coefficients between the Japanese and the US or Canadian stock markets in this paper. More specifically, the focus of our investigations is on the US, Canadian, and the Japanese stock markets.

\section{Research Design and Methodology}

In this section, the design and the methodology of our research are explained. First, our full weekly sample period is from 24 November 2001 through 11 February 2012. In order to implement our empirical study, we first divide our full samples into the following four sub-periods. More specifically, they are two sub-periods which include 178 weeks (These are before the US Lehman Shock), one sub-period which includes 178 weeks (This is after the Lehman Shock), and one sub-period which includes 30 weeks (This is also after the Lehman Shock). That is, these four sub-periods that we analyze are (i) the term from 24 November 2001 through 16 April 2005 (This period is denoted as ‘the first term’ hereafter.); (ii) the term from 23 April, 2005 through 13 September 2008 (This period is denoted as 'the middle term' hereafter.); (iii) the term from 20 September 2008 through 11 February 2012 (This period is denoted as 'the latest term' hereafter.); (iv) the term from 20 September 2008 through 11 April 2009 (This period is denoted as ‘the LS term’ hereafter.). The last sub-period that 
includes 30 weeks is the short-term sample period right after the Lehman Shock. It is considered that this last sub-period is largely influenced by the Lehman Shock.

Using the above four sub-periods and the data introduced above, the Welch's tests are performed. This is to compare the stock returns' correlation coefficients between the Japanese and the US or Canadian equity markets in each sub-period. In our tests, the historical correlation coefficients as to past 20 weeks are used. As we documented, the analysis in this paper includesthe Lehman Shock period when correlations among international stock markets drastically change. Hence in order to avoid the difficulties in estimations of technical models or measures in such periods, this paper does not use any econometrical models or measures. We also note that ourempirical analyses exploited simple historical correlation coefficients derive strongly robust evidence as we document in the next section.

Further, the null hypothesis of our Welch's tests is that, in two sub-periods compared, the correlation coefficients' mean value of two markets' returns are equal. Contrary to this hypothesis, the alternative hypothesis of our Welch's tests is that, in two sub-periods compared, the correlation coefficients' mean value of two markets' returns are not equal. Documenting the alternative hypotheses in our five Welch's tests more specifically, those are as follows: (i) The correlation coefficients' average value in 'the first term' is lower than the correlation coefficients' average value in 'the middle term'; (ii) The correlation coefficients' average value in 'the first term' is lower than the correlation coefficients' average in 'the latest term'; (iii) The correlation coefficients' average value in 'the first term' is lower than the average in 'the LS term'; (iv) The correlation coefficients' average value in 'the middle term' is lower than the average in 'the LS term'; (v) The correlation coefficients' average value in 'the latest term' is lower than the average in 'the LS term'. Moreover, the time-series developments of the correlation coefficients of returns between the Japanese and the US or Canadian stock markets are exhibited in Panels A andB in Figure 1.

\section{Empirical Results}

Empirical results are demonstrated in this section. We describe our empirical results shown in Table 1 as follows. (i) Firstly, as indicated in Panel B of Tables 1, the correlation coefficients of equity returns in the Japanese markets and the US or Canadian markets increase in 'the middle term' than in 'the first term'. (ii) Secondly, as shown in Panel C of Table 1, the correlations of the Japanese stock markets and the US or Canadian stock markets are higher in 'the latest term' than in 'the first term'. (iii) Thirdly, as displayed in Panel D of Table 1, the correlations of the Japanese stock markets and the US or Canadian equity markets are higher in 'the LS term' than in 'the first term'. (iv)Fourth, as shown in Panel E of Table 1, the correlations between the Japanese stock markets and the US or Canadian markets are higher in 'the LS term' than in 'the middle term'. (v) Finally, as exhibited in Panel F of Table 1, the correlations between the Japanese stock markets and the US or Canadian stock markets are higher in 'the LS term' than in 'the latest term'.

To sum up, our investigations offer the evidence that the covariations of stock returns between the Japanese markets and the US or Canadian markets recently gradually increased. These findings are always supported with strong statistical significance. Moreover, in the 
period right after the Lehman Shock, these covariations of stock returns increased in particular. This result is also supported with strong statistical significance. We note that all our empirical results are statistically strongly supported and always supply very clear evidence.

Panel A. USA and Japan

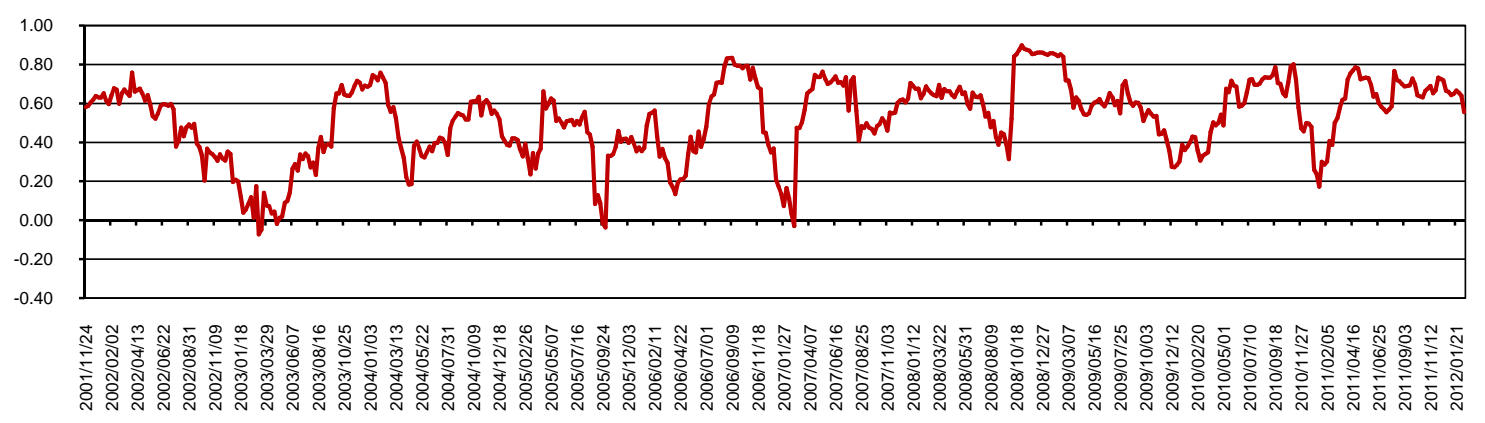

Panel B. Canada and Japan



Figure 1.Correlation Coefficients with the Japanese Stock Markets.

\section{Interpretation and Implications}

The empirical results explained above suggest that the international diversifications in stock portfolios recently become less important in portfolio management. However, the value changes of foreign stocks depend on the time-varying changes of foreign exchange rates. Hence more careful look at the relationships between the risk of foreign exchange rates and expected stock returns shall be more and more important for the future equity portfolio management. This is the first implication derived from our empirical study. Hence we note that it is important to scrutinize the time-varying relations between exchange rates and stock returns in international countries, in particular, in the recent period. Further, we consider that this line of research shall be our future another task. 
Table 1. The Results of Welch's Tests: The Linkage with the USA and Canada

\begin{tabular}{|c|c|c|c|}
\hline Sample Periods & Statistic & USA & Canada \\
\hline \multirow{2}{*}{$\begin{array}{l}\text { November 24, } 2001 \\
\text { to April 16, } 2005\end{array}$} & Mean & 0.4405 & 0.4497 \\
\hline & SD & 0.1986 & 0.1674 \\
\hline \multirow{2}{*}{$\begin{array}{l}\text { April 23, } 2005 \text { to } \\
\text { September 13, } 2008\end{array}$} & Mean & 0.5161 & 0.5214 \\
\hline & SD & 0.1922 & 0.1942 \\
\hline \multirow{2}{*}{$\begin{array}{l}\text { September 20, } 2008 \\
\text { to February 11, } 2012\end{array}$} & Mean & 0.6140 & 0.5586 \\
\hline & SD & 0.1586 & 0.2077 \\
\hline \multirow{2}{*}{$\begin{array}{l}\text { September 20, } 2008 \\
\text { to April 11, } 2009\end{array}$} & Mean & 0.7641 & 0.7463 \\
\hline & SD & 0.1569 & 0.0816 \\
\hline
\end{tabular}

Panel B Results for Welch's Tests: The Mean Value of the Correlation Coefficients of Returns for November 24, 2001 to April 16, 2005 < The Mean Value of the Correlation Coefficients of Returns for April 23, 2005 to September 13, 2008

\begin{tabular}{lcc}
\hline$t$-value for Welch's tests & $3.6524^{* * *}$ & $3.7289^{* * *}$ \\
$p$-value & 0.0001 & 0.0001
\end{tabular}

Panel C Results for Welch's Tests: The Mean Value of the Correlation Coefficients of Returns for November 24, 2001 to April 16, 2005 < The Mean Value of the Correlation Coefficients of Returns for September 20, 2008 to February 11, 2012

\begin{tabular}{lcc}
\hline$t$-value for Welch's tests & $9.1079^{* * *}$ & $5.4456^{* * *}$ \\
$p$-value & 0.0000 & 0.0000 \\
\hline Panel D & Results for Welch's Tests: The Mean Value of the Correlation Coefficients of Returns for November 24, 2001 to \\
April 16, $2005<$ The Mean Value of the Correlation Coefficients of Returns for September 20, 2008 to April 11, 2009 \\
\hline$t$-value for Welch's tests & $10.0281^{* * *}$ & $15.2225^{* * *}$ \\
$p$-value & 0.0000 & 0.0000 \\
\hline
\end{tabular}

Panel E Results for Welch's Tests: The Mean Value of the Correlation Coefficients of Returns for April 23, 2005 to September13, $2008<$ The Mean Value of the Correlation Coefficients of Returns for September 20, 2008 to April 11, 2009

\begin{tabular}{lcc}
\hline$t$-value for Welch's tests & $7.7363^{* * *}$ & $10.7987^{* * *}$ \\
$p$-value & 0.0000 & 0.0000
\end{tabular}

Panel F Results for Welch's Tests: The Mean Value of the Correlation Coefficients of Returns for September 20, 2008 to February 11, 2012 < The Mean Value of the Correlation Coefficients of Returns for September 20, 2008 to April 11, 2009

\begin{tabular}{lcc}
\hline$t$-value for Welch's tests & $4.8423^{* * *}$ & $8.7086^{* * *}$ \\
$p$-value & 0.0000 & 0.0000
\end{tabular}

Notes: In panel A, 'Mean' denotes the mean values of 20 week historical correlation coefficients between stock returns in the Japanese equity markets and the US markets or Canadian markets. Further, 'SD' means the standard deviations of 20 week historical correlation coefficients between stock returns in the Japanese equity markets and the US markets or Canadian markets. In panels $\mathrm{B}$ to $\mathrm{F},{ }^{* * *}$ denotes the statistical significance at the $1 \%$ level, ${ }^{* *}$ denotes the statistical significance at the $5 \%$ level, and $*$ denotes the statistical significance at the $10 \%$ level, respectively.

Further, increasing market integration of international stock markets suggested by our tests implies that other non-traditional asset classes such as real estate or commodities are also increasingly important for the future management of portfolios, where investment assets are not limited to only equities. We also consider that the investment strategies of hedge funds should be carefully consulted when we plan the short-term investment strategies. 
Furthermore, the particular increases of the comovements among the highly stressed international equity markets indicate that the importance of the ability to forecast market crashes and financial crises timely by some effective indicators. For example, to carefully watch the investor sentiment might be highly effective for forecasting these extreme market frictions or stresses. The intertemporal relations among market sentiment, real economy, and stock markets would be also important for understanding the real trends of macroeconomy and stock markets.

\section{Summary and Conclusions}

In this paper, we implemented the empirical tests with regard to the time-varying stock return connections between the Japanese markets and the US or Canadian markets. In our empirical examinations, the focus was particularly on the stock return correlations' differences in the periods which are before and after the Lehman Shock. Our empirical tests performed in this paper derived the following novel contributions.

1. Firstly, it was statistically strongly significantly revealed that recently, the stock return correlations between the Japanese and the US or Canadian equity markets gradually increased.

2. Secondly, it was empirically derived that the time-varying linkage between stock returns of the Japanese markets and the US or Canadian markets increased, in particular, in the sub-period right after the Lehman Shock.

As we summarized above, the statistically strongly significant facts from our formal tests in this study will contribute to the body of academic research in economics, business, and finance. It is considered that the future related investigations by exploiting our findings and other related data shall be also valuable, and these analyses are our future works.

\section{Acknowledgement}

The author acknowledges the Japan Society for the Promotion of Science for their generous financial assistance for this research. In addition, I also thank anonymous referees and the Editor for their kind comments to this paper. Furthermore, I greatly appreciate the kind invitation from the Editors to write to this journal.

\section{References}

Allen, F. \& Gale, D. (2000). Financial contagion. Journal of Political Economy, 108, 1-33.

Allen, F., Babus, A. \&Carletti, E. Asset commonality, debt maturity and systemic risk. Journal of Financial Economics, forthcoming. http://dx.doi.org/10.1016/j.jfineco.2011.07.003

Bekaert, G. \& Harvey, C. (1995). Time-varying world market integration. Journal of Finance, 50, 403-444. http://dx.doi.org/10.2307/2329414

Billio, M., Getmansky, M., Lo, A.W. \&Pelizzon, L. Econometric measures of connectedness and systemic risk in the finance and insurance sectors. Journal of Financial Economics, forthcoming. http://dx.doi.org/10.1016/j.jfineco.2011.12.010 
Forbes, K.J. \&Rigobon, R. (2002). No contagion, only interdependence: measuring stock market comovements. Journal of Finance, 57, 2223-2261. http://dx.doi.org/10.1111/0022-1082.00494

Hardouvelis, G., Malliaropoulos, D. \& Priestley, R. (2006). EMU and European stock market integrations. Journal of Business, 79, 365-392. http://dx.doi.org/10.1086/497414

Pukthuanthong, K. \& Roll, R. (2009). Global market integration: An alternative measure and its application. Journal of Financial Economics, 94, 214-232. http://dx.doi.org/10.1016/j.jfineco.2008.12.004

Solnik, B. (1974). The international pricing of risk: an empirical investigation of the world capital market structure. Journal of Finance, 29, 365-378.

\section{Copyright Disclaimer}

Copyright reserved by the author(s).

This article is an open-access article distributed under the terms and conditions of the Creative Commons Attribution license (http://creativecommons.org/licenses/by/3.0/). 